\title{
The Educating Role of Visual Arts
}

\author{
Sandra Palhares * \\ University of Minho
}

\begin{abstract}
This article discusses contemporary visual arts education current changes. Visual Arts Education is frequently underestimated by most European Curriculum which often gave and still gives priority to other knowledge areas. Nevertheless, culture industries like museums and a wide range of culture and social organizations are doing the opposite, leading visual art education to an increasingly dissemination, even if it is always less than we all expect. This article also focus on a current shift and which seems to be a kind of paradox: visual art education services from alternative culture institutions are becoming integrated on school activities. By recognizing Visual Art Education Value, culture institutions are trying to develop different approaches in order to engage visual arts with communities. By informing and promoting creative thinking, they are trying to reach community involvement and, consequently, breaking down barriers when necessary. In a more and more globalized world, it is urgent to rethink culture, ethnical, social, economical and political diversities and here is where visual arts education can become a more active player. Art always allowed man to create different worlds in our world as Nelson Goodman affirmed. By creating new worlds, art offers possibilities on new world perspectives and therefore it also might make possible a great miracle, which is the possibility of changing into a better world! Isn't that what next Documenta 14 is doing? Documenta 14, Kassel, considered the world's largest and most prestigious exhibition of contemporary art, will be held in Athens, Greece, and Kassel, Germany, under the following theme: Learning from Athens. Both - visual art education and contemporary art - seem to share this wish and determination in changing to a better world by implicating local, national and international community. And Art always seemed to be a great 'educator' throughout mankind history.
\end{abstract}

\section{Key-words}

Visual Art Education, Art, Culture Institutions, Change.

\footnotetext{
* Docente no Instituto de Educação da Universidade do Minho, Braga: sandrapalhares@ie.uminho.pr.
} 
Visual Arts Education is frequently underestimated by most European Curriculum which often gave and still gives priority to other knowledge areas. Nevertheless, culture industries like museums and a wide range of culture and social organizations are doing the opposite, leading visual art education to an increasingly dissemination, even if it is always less than we all expect. Nowadays a current shift seems to be a kind of paradox: visual art education services from alternative culture institutions are becoming integrated on school activities. By recognizing Visual Art Education Value, culture institutions are trying to develop different approaches in order to engage visual arts with communities. By informing and promoting creative thinking, they are trying to reach community involvement and, consequently, breaking down barriers when necessary. In a more and more globalized world, it is urgent to rethink culture, ethnical, social, economical and political diversities and here is where visual arts education can become a more active player. Art always allowed man to create different worlds in our world as Nelson Goodman affirmed. By creating new worlds, art offers possibilities on new world perspectives and therefore it also might make possible a great miracle, which is the possibility of changing into a better world! Isn't that what next Documenta 14, Kassel is doing? Documenta 14, Kassel, considered the world's largest and most prestigious exhibition of contemporary art, will be held in Athens, Greece, and Kassel, Germany, under the following theme: Learning from Athens. Both - visual art education and contemporary art - seem to share this wish and determination in changing to a better world by implicating local, national and international community. And Art always seemed to be a great 'educator' throughout mankind history and perhaps that's one of art's strength. I remember when I was a child I used to be fascinated by the art reproductions on media like magazines, newspapers, books or on TV. Sometimes, not very often, I was 
able to see them directly on Museums or galleries exhibitions and I was not disappointed. Honestly and just between us, I just got disappointed with Mona Lisa's scale when I got the chance to see it in Louvre. Where do I want to get with this point? Even though by that time the world was becoming more and more full of images, I still felt art images were different from all others. But what does make it so different and special? Along humankind history and for a long time, paintings and sculptures, were the only medium which allowed all kind of world representation. But then, throughout time, images production escape artist's control and, suddenly, everyone can produce images due to recent and amazing technology development. Not only images production became more accessible to everyone but its circulation on our contemporary globalized world also became more and more unceasing. Despite the fact, we live saturated by images, art often still stops our attention and often overcomes any other kind of image once, and often, we seemed to give more attention to an art image than to any other, even when competing with spectacular images usually provided by entertainment and publicity industries. Still then and most of the time, art overcomes it. We might argue art's strength has to do with that 'extra' attention an art object captures from us- we often given art object the 'benefit of doubt'. Whether we like it or not, whether we understand it or not, whether it causes any kind of emotion, good or bad sensation, we often give art a second chance and we look again as if something has missed us at a first glance. By contemplating again we make an effort to decode a hypothetical message or to perceive a sensation even if it happens to be a purely aesthetic one. And that's when, through contemplation, it might occur what we mentioned earlier: Visual Art educator role's effect. And, that's when we can really understand that moment as a chance for a change: by contemplating art, Men puts him in a position of a certain kind of vulnerability for difference and once we 'experience' the difference, we will be most likely to accept the difference! Visual Arts sometimes make it possible to happen. When contemplating, we kind of meditate, reflect, consider and somehow 
absorb. In the end, we embody - even if only partially- what we contemplate and therefore, we kind of accept it. Every day it happens the opposite: we are constantly zapping, passing by and seeing all and nothing, stopping where is most impressionable. Following the previous perspective, it is precisely the other way around 'effect' which still makes art so strikingly: art traps us!

Now, if we start from the very beginning, from Visual Arts integration on education, it will be more likely to happen. By integrating Visual Arts on Curriculum programs, and on any kind of culture alternative educational services, it will be much easier to achieve the main goal which is to enable humankind to experience and accept differences. Despite the fact that Art Museums and its Educational Services increased all over the world in the past years in our globalized and hyper-communicated world, differences seem to be increasing and becoming more and more evident and, even more strident. Here and now is where we should reconsider Visual Arts Education's role. If most of Curriculums decreased art role on it, its absence is being partial and progressively supplanted by the alternative art educational services. However, it is not enough and, unfortunately, it does not reach all of us as we would expect and, it is not 'all inclusive'. It is also more likely to happen in developed urban and cosmopolitan cities like London where, immediately, we take as a good example Tate Modern active Educational Service. Returning to the beginning and picking the Documenta Kassel 's sample we can also understand better how Visual Art education dissemination can happen and spread over society through different approaches. Sometimes, as this example illustrates it does not necessary need to happen in a school environment or through a planned political educational programme. It might be raise from unexpected and 'unofficial' education institutions like contemporary museums or rise from unexpected curatorial ideas like Learning from Athens. Documenta Kassel. 
Nevertheless, and as pointed out earlier, it is not reachable for all. Independently of any unpredictable political changes that might happen until the upcoming Documenta Kassel, one thing we can be sure: it will have more media attention than previous editions because of its assumed and obvious political aesthetic engagement. Regardless its predictable media impact, probably it won't reach all of us as education does. Despite being considered the world's largest and most prestigious exhibition of contemporary art, its audience is not as large as we wish even though is still quite impressive. And that's why it is so important to provide Curriculum with Visual Arts contents. In an unequal crescent Europe which "Learning from Athens. Documenta Kassel" seems to evoke, education seems to be the right and the only way to get there. Only through education programmes we can widen up and, hopefully, might reach all. As far I remember there is no other way of being more democratic than to provide the right to education. Museums, exhibitions have costs and there is always an entrance ticket to pay which is not affordable to all publics. Besides, its specific programmes suit an updated demanding audience which profile is quite different from a more general public. These art institutions are part of the so called culture industries and cannot survive without incomings, they have complex structures which need to be financed otherwise they are not sustainable and cannot open to public. I am not arguing about its nature or purpose. What I consider important to underline and point out is that education cannot be supplanted by any other kind of charged 'service', even if allocated in any sort of educational category offered by Museums. Museums can offer a wide range of art and experiences but so far it cannot offer a continuous programme as education provide. Both have different purposes, they cannot replace each other but they might complement each other as many theorists and scholars recommended. This perspective of seeing education as a continuous process does not disregard any change on traditional educational processes. 
Because of the Visual Art Education general lack on most European Curriculum it is difficult to demonstrate its impact and importance and still remains a widespread adherence to its absence. Some may maintain that there should be alternatives to this increasing educational lack. I entirely agree and subscribe but it is still not enough. That's why the current shift above mentioned seems to be a kind of paradox once visual art education services from alternative culture institutions are becoming integrated on school activities where Visual Arts contents have been gradually decreased in most educational programmes. By the other way around, some parents seem to become more and more aware of the importance of Visual Arts and Visual Arts education impact on childhood development, understanding its contribution for encouraging self-confidence, autonomy, difference and difference on expression itself. Once again, I recall: those who benefit from educational services are more often an elite or privileged because museums are located mainly in developed and wealthy cities. Even other kind of alternative Visual Arts community education programmes services are normally 'born' precisely on big multicultural and 'supposedly' more developed cities. But what happens with small communities which are far away from these centres? Portugal could be a micro metaphor for the macro unequal contemporary Europe posed through "Learning from Athens. Documenta Kassel': the interior Portuguese landscape resembles Athens and, on the other hand, big coast cities as Lisbon seem to have a parallel with Kassel. Should we keep going on perpetuating differences? The lack of equality or dissimilarity is the origin of world conflicts and we seem to forget it very often. If the Museums and the exhibitions are the only Visual Arts future alternative to traditional education programmes, instead of increasing its accessibility, it will make it even more difficult and less affordable for the great majority of European population. That is why I insist that Curriculum programmes should take Visual Arts integration in consideration and reformulate its content in order to widen up mentalities 
and hopefully minimize culture differences and, therefore, contributing and building a better world. A central issue of human rights education from UNESCO Constitution is the right to education. Let's make it better throughout Visual Arts Education. With hope we can mediate contemporary issues in order to embrace a sustainable future. And, finally and hopefully, making a change for Europe's sake!

Artigo recebido em dezembro de 2015. Aprovado em abril de 2016 